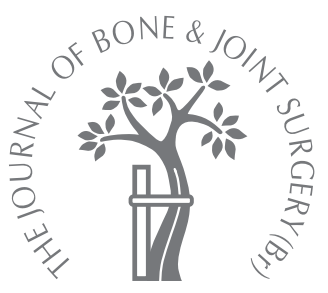

J. H. H. Chan, M. S. Ballal,

S. Dheerendra, J. Sanchez-Ballester, R. V. Pydisetty

From St Helens and Knowsley Teaching Hospitals NHS Trust, Prescot, United Kingdom
I. H. H. Chan, MRCS,

Specialty Registrar in Trauma and Orthopaedics

M. S. Ballal, MRCS(Ed),

Specialty Registrar in Trauma

and Orthopaedics

S. Dheerendra, MRCS,

Specialty Registrar in Trauma

and Orthopaedics

I. Sanchez-Ballester,

FRCS(Ed), FRCS(Orth),

Consultant Orthopaedic

Surgeon

R. V. Pydisetty, MS(Orth),

FRCS(Tr\&Orth), MCh(Liv),

Consultant Orthopaedic

Surgeon

St Helens \& Knowsley Teaching

Hospitals NHS Trust,

Warrington Road, Prescot

Merseyside L35 5DR, UK.

Correspondence should be sent to $\mathrm{Mr} \mathrm{J}$. H. H. Chan; e-mail: jhhchan@doctors.org.uk

(c)2011 British Editorial Society of Bone and Joint Surgery doi:10.1302/0301-620X.93B2. $25770 \$ 2.00$

$J$ Bone Joint Surg [Br] 2011;93-B:274-6.

Received 26 August 2010

Accepted 4 October 2010

\title{
Entrapment of the sciatic nerve following closed reduction of a dislocated revision total hip replacement
}

\author{
Injury to the sciatic nerve following closed manipulation of a dislocated total hip \\ replacement is rare. We present such a case in an elderly patient with partial recovery \\ following exploration and release of the nerve.
}

Injury to the sciatic nerve is a recognised complication of both dislocated native hips and prosthetic total hip replacements (THRs). ${ }^{1-3}$ The standard management involves closed reduction, which usually has a low rate of complications. ${ }^{4}$ We describe a case with an unusual complication involving the sciatic nerve following closed reduction of a revision THR.

\section{Case report}

An 84-year-old woman was referred with sudden, severe pain in her left hip after attempting to stand from a seated position. She had a revision of a THR on the same side, which had been performed four years before. The indication for the primary THR was osteoarthritis, and it was revised because of aseptic loosening. Both procedures were performed via an anterolateral approach. On examination she was in pain and

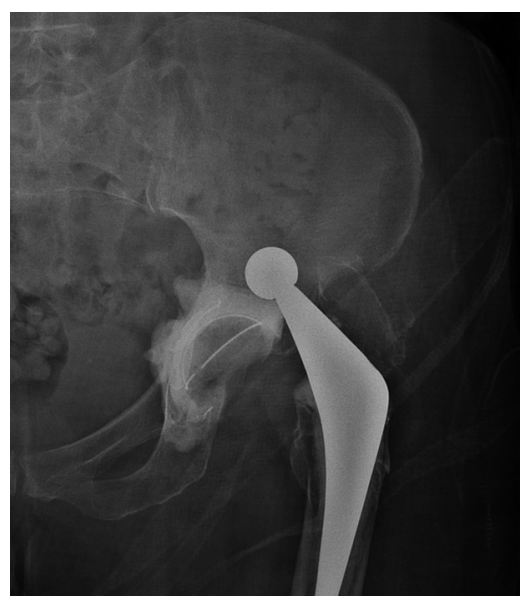

Fig. 1

Pre-operative anteroposterior radiograph showing the dislocated revision total hip replacement with a longstanding nonunion of the greater trochanter. her left leg was shortened and internally rotated. There was no neurovascular deficit. An anteroposterior (AP) radiograph of the pelvis revealed a posterior dislocation of the THR with a longstanding nonunion of the osteotomy of the greater trochanter (Fig. 1). The hip was reduced successfully under a general anaesthesia following several attempts and was found to be stable in all directions. Fluoroscopic images revealed a concentric reduction (Fig. 2).

Post-operatively, she complained of severe pain in the left buttock and proximal thigh which radiated down to her left foot. The pain persisted and she was reluctant to mobilise. The pain increased if she attempted to lift or rotate her left leg and she preferred to keep it in slight external rotation and flexion. Further assessment revealed absent plantar- and dorsiflexion of the ankle with decreased sensation in both the L5 and S1 dermatomes. It was difficult to assess neurological function proximal to the knee because of pain. There was no vascular compromise. A diagnosis of neuropraxia of the sciatic nerve was made and it was decided to manage this conservatively. However, her neurological status did not improve and her pain worsened over the next four days in spite of regular analgesia. Further radiographs confirmed a concentric reduction and no obvious fractures. An ultrasound study of her left leg revealed a complex collection within the hamstring compartment, although the sciatic nerve could not be identified. The collection was thought to be haematoma compressing the sciatic nerve and surgical exploration was planned.

Operation was performed via an extended posterior approach six days following the closed reduction. However, the sciatic nerve was not visualised because of scar tissue from previous surgery. An arthrotomy was made and the prosthesis was dislocated. The sciatic 


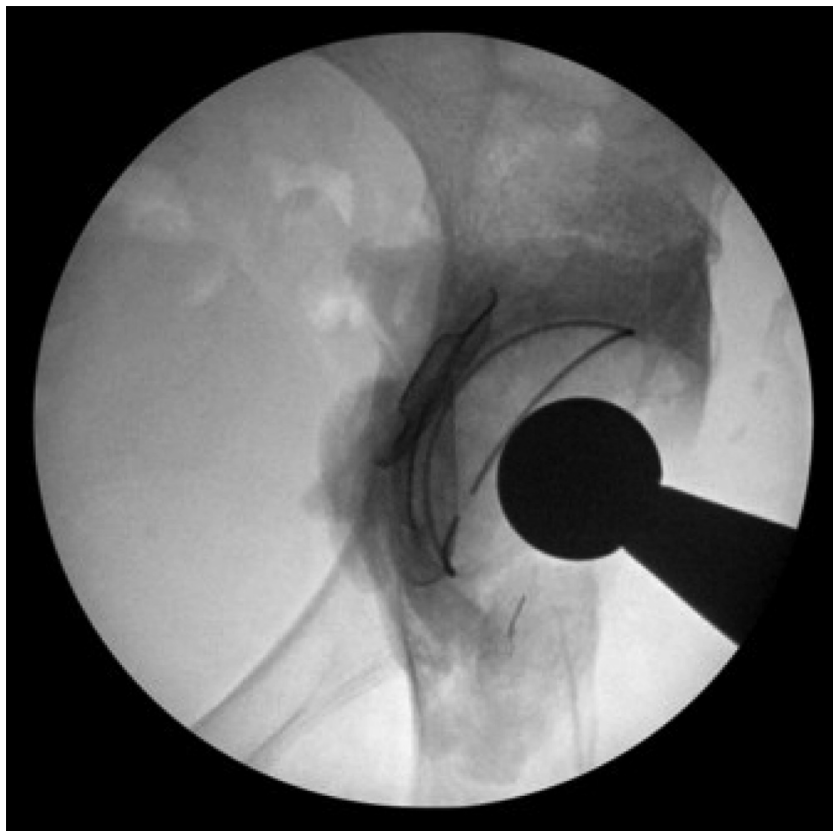

Fig. 2

Fluoroscopic image showing reduction of the dislocated total hip replacement with no features of soft-tissue interposition.

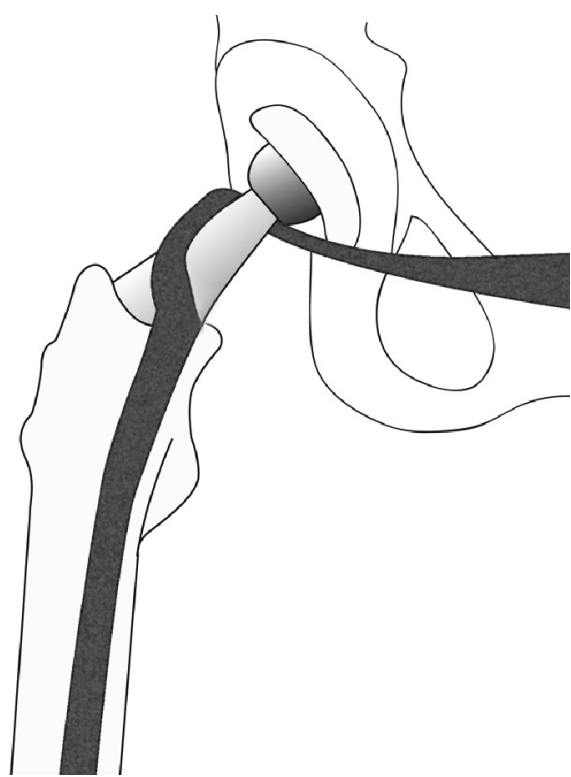

Fig. 3

Diagram of the posterior view of the left hip showing the sciatic nerve trapped anteriorly and wrapped around the neck of the femoral component. nerve was found to be stretched and was located anterior to the hip join, wrapped around the neck of the femoral component (Fig. 3). The nerve was freed and, although in continuity, was severely bruised. It was traced distally and the haematoma in the posterior compartment was evacuated. Post-operatively, her pain, hamstring and quadriceps function improved significantly but the sensory deficit in both the L4 and L5 dermatomes and the foot drop persisted, with power improving to 1 out of 5 on the MRC scale. She was mobilising with a Zimmer frame prior to being discharged for further rehabilitation with a foot drop splint and she remains under review.

\section{Discussion}

The incidence of dislocation following a THR varies between $1 \%$ and $3.2 \%{ }^{3,5,6}$ in primary procedures and rises to $7.4 \%$ in revisions. ${ }^{7}$ Nerve injuries are a recognised complication following dislocation of a joint. The sciatic nerve is at particular risk of injury posterior fracture-dislocations of the hip joint ${ }^{1-3,7-9}$ where its incidence varies between $0.7 \%$ and $3.7 \% .^{10,11}$

To our knowledge, there are only three reported cases in the English literature of injury to the sciatic nerve following closed reduction of a dislocated THR. ${ }^{2,12,13}$ Lazansky, ${ }^{2}$ in his review of 501 cases of Charnley THRs performed over a period of six years, reported a case of incomplete sciatic nerve palsy following closed reduction of a post-operative dislocation. It was not mentioned whether this was treated conservatively or explored surgically.
Complete palsy of the sciatic nerve following closed reduction of such dislocations has been reported in two other studies. ${ }^{12,13}$ Stockley and Bickerstaff ${ }^{12}$ described a similar case to our patient, with acute complete sciatic nerve palsy in a 74-year-old woman. She had a revision THR via a trochanteric osteotomy, which dislocated posteriorly 18 hours after operation. She developed a complete sciatic nerve palsy following closed reduction. The time from dislocation to exploration and release of the nerve was not stated, but by three weeks she had regained near-normal function. In contrast, the second reported case was of a 66year-old woman who had a 14-month history of a sciatic nerve palsy following closed reduction of a THR that had dislocated one month post-operatively. ${ }^{13}$ This patient's pain improved rapidly following surgery, but at 25 months after the initial injury, 11 months after operation, she still had no improvement in motor function and had residual paraesthesia over the lateral border of her foot. In both cases as well as ours, the sciatic nerve was wrapped around the front of the neck of the femoral component (Table I).

In our case, the patient had no symptoms or signs of a sciatic nerve palsy at the time of presentation with a dislocated hip replacement, and these only appeared once the dislocated prosthesis had been reduced by closed methods. This implies that the sciatic nerve was trapped around the femoral component as the hip was being reduced. This may have been easier in the presence of the non-united greater trochanter. Manoeuvres involving circumduction during closed reduction can facilitate this phenomenon. ${ }^{1}$ The relatively long period between revision and dislocation 
Table I. Details of reported cases of sciatic nerve palsy following closed reduction of a dislocated total hip replacement

\begin{tabular}{|c|c|c|c|c|c|c|}
\hline Author/s & $\begin{array}{l}\text { Number of } \\
\text { cases }\end{array}$ & $\begin{array}{l}\text { Type of } \\
\text { palsy }\end{array}$ & $\begin{array}{l}\text { Time of dislocation } \\
\text { after total hip } \\
\text { replacement }\end{array}$ & $\begin{array}{l}\text { Time from reduction } \\
\text { to exploration of } \\
\text { nerve }\end{array}$ & $\begin{array}{l}\text { Approach in initial } \\
\text { surgery }\end{array}$ & $\begin{array}{l}\text { Type of hip } \\
\text { replacement }\end{array}$ \\
\hline Lazansky $^{2}$ & 1 & Partial & Not mentioned & Not explored & Not mentioned & Primary \\
\hline $\begin{array}{l}\text { Stockley and } \\
\text { Bickerstaff }\end{array}$ & 1 & Complete & 18 hours & Not mentioned & Trochanteric osteotomy & Revision \\
\hline Leversedge et $\mathrm{al}^{13}$ & 1 & Complete & 1 month & 14 months & Posterior & Primary \\
\hline Chan et al ${ }^{*}$ & 1 & Complete & 4 years & 6 days & Trochanteric osteotomy & Revision \\
\hline
\end{tabular}

would have allowed the soft tissues around the hip to scar significantly which can also place the sciatic nerve at risk of a tension injury. ${ }^{14}$

The symptom of severe pain and signs of a complete motor palsy immediately post-operatively suggested entrapment of the nerve within a joint rather than a transient neuropraxia. In this situation, there is little to be gained by performing further radiological investigations. Early exploration is recommended in these cases. ${ }^{12,15}$

Significant damage to the nerve can occur following entrapment around the femoral component and neurological recovery is variable. However, the severe preoperative pain that occurs from entrapment of the nerve usually responds very quickly to exploration and release.

Immediate operative exploration of the sciatic nerve should be performed when there is a complete palsy following closed reduction of a dislocated THR. In patients with distorted anatomy following previous surgery, one should consider dislocating the hip and ruling out entrapment when the nerve cannot be localised in its normal path.

No benefits in any form have been received or will be received from a commercial party related directly or indirectly to the subject of this article.

\section{References}

1. Epstein HC. Posterior fracture-dislocations of the hip: long-term follow-up. J Bone Joint Surg [Am] 1974;56-A:1103-27.
2. Lazansky MG. Complications revisited: the debit side of total hip replacement. Clin Orthop 1973;95:96-103.

3. Cornwall R, Radomisli TE. Nerve injury in traumatic dislocation of the hip. Clin Orthop 2000;377:84-91.

4. Soong M, Rubash HE, Macaulay W. Dislocation after total hip arthroplasty. J Am Acad Orthop Surg 2004;12:314-21.

5. Woo RY, Morrey BF. Dislocations after total hip arthroplasty. J Bone Joint Surg [Am] 1982;64-A:1295-306.

6. Coventry MB, Beckenbaugh RD, Nolan DR, Ilstrup DM. 2,012 total hip arthroplasties: a study of postoperative course and early complications. J Bone Joint Surg [Am] 1974;56-A:273-84.

7. Alberton GM, High WA, Morrey BF. Dislocation after revision total hip arthroplasty: an analysis of risk factors and treatment options. J Bone Joint Surg [Am] 2002;84-A:1788-92.

8. Dhillon MS, Nagi ON. Sciatic nerve palsy associated with total hip arthroplasty. Ital $J$ Orthop Traumatol 1992;18:521-6.

9. DeHart MM, Riley LH Jr. Nerve injuries in total hip arthroplasty. J Am Acad Orthop Surg 1999; 7:101-11.

10. Weber ER, Daube JR, Coventry MB. Peripheral neuropathies associated with total hip arthroplasty. J Bone Joint Surg [Am] 1976;58-A:66-9.

11. Wilson JN, Scales JT. The Stanmore metal on metal total hip prosthesis using a three pin type cup: a follow-up of 100 arthroplasties over nine years. Clin Orthop 1973;95:239-49.

12. Stockley I, Bickerstaff D. Sciatic nerve palsy following reduction of a dislocated prosthesis: brief report. J Bone Joint Surg [Br] 1988;70-B:329-30.

13. Leversedge FJ, Gelberman RH, Clohisy JC. Entrapment of the sciatic nerve by the femoral neck following closed reduction of a hip prosthesis: a case report. J Bone Joint Surg [Am] 2002;84-A:1210-13.

14. Lundborg G, Rydevik B. Effects of stretching the tibial nerve of the rabbit: a preliminary study of the intraneural circulation and the barrier function of the perineurium. $J$ Bone Joint Surg [Br] 1973;55-B:380-401.

15. Fleming RE Jr, Michelson CB, Stinchfield FE. Sciatic paralysis: a complication of bleeding following hip surgery. J Bone Joint Surg [Am] 1979;61-A:37-9. 